\title{
Transgenerational effects on development following microplastic exposure in Drosophila melanogaster
}

\author{
Eva Jimenez-Guri ${ }^{\text {Corresp., } 1,2}{ }^{2}$, Katherine E Roberts ${ }^{2}$, Francisca C García ${ }^{2}$, Maximiliano Tourmente ${ }^{3,4}$, Ben Longdon ${ }^{2}$, \\ Brendan J Godley ${ }^{2}$ \\ ${ }^{1}$ Biology and Evolution of Marine Organisms (BEOM), Stazione Zoologica Anton Dhorn, Naples, Italy \\ ${ }^{2}$ Centre for Ecology and Conservation, College of Life and Environmental Sciences, University of Exeter Cornwall Campus, University of Exeter, Penryn, \\ Cornwall, United Kingdom \\ 3 Institute for Biological and Technological Research (IIByT), National Scientific and Technical Research Council (CONICET), Córdoba, Argentina \\ ${ }^{4}$ Centre for Cell and Molecular Biology. Faculty of Exact, Physical, and Natural Sciences, University of Córdoba, Córdoba, Argentina \\ Corresponding Author: Eva Jimenez-Guri \\ Email address: e.jimenez-guri@exeter.ac.uk
}

Background. Plastic pollution affects all ecosystems, and detrimental effects to animals have been reported in a growing number of studies. However, there is a paucity of evidence for effects on terrestrial animals in comparison to those in the marine realm.

Methods. We used the fly Drosophila melanogaster to study the effects that exposure to plastics may have on life history traits and immune response. We reared flies in four conditions: In media containing $1 \%$ virgin polyethylene, with no chemical additives; in media supplemented with $1 \%$ or $4 \%$ polyvinyl chloride, known to have a high content of added chemicals; and control flies in non-supplemented media. Plastic particle size ranged from $23-500 \mu \mathrm{m}$. We studied fly survival to viral infection, the length of the larval and pupal stage, sex ratios, fertility and the size of the resultant adult flies. We then performed crossings of F1 flies in non-supplemented media and looked at the life history traits of the F2.

Results. Flies treated with plastics in the food media showed changes in fertility and sex ratio, but showed no differences in developmental times, adult size or the capacity to fight infections in comparison with controls. However, the offspring of treated flies reared in non-supplemented food had shorter life cycles, and those coming from both polyvinyl chloride treatments were smaller than those offspring of controls. 
1 Transgenerational effects on development following microplastic exposure in Drosophila

2 melanogaster

3

4 Eva Jimenez-Guri ${ }^{1,2 *}$, Katherine E Roberts ${ }^{1}$, Francisca C García ${ }^{1}$, Maximiliano Tourmente ${ }^{3,4}$, 5 Ben Longdon ${ }^{1}$, Brendan J Godley ${ }^{1}$.

$6{ }^{1}$ Centre for Ecology and Conservation, College of Life \& Environmental Sciences, University of

7 Exeter, Penryn Campus, Penryn, Cornwall, United Kingdom

8 'Biology and Evolution of Marine Organisms (BEOM), Stazione Zoologica Anton Dohrn, Villa

9 Comunale, 80121, Naples, Italy

${ }^{3}$ Centre for Cell and Molecular Biology. Faculty of Exact, Physical, and Natural Sciences -

11 University of Córdoba. Vélez Sarsfield 1611, X5016GCA, Córdoba, Argentina.

${ }^{4}$ Institute for Biological and Technological Research (IIBYT) - National Scientific and Technical Research Council (CONICET). Vélez Sarsfield 1611, X5016GCA, Córdoba, Argentina.

*Author for correspondence: e.jimenez-guri@exeter.ac.uk

Abstract

Background. Plastic pollution affects all ecosystems, and detrimental effects to animals have been reported in a growing number of studies. However, there is a paucity of evidence for effects on terrestrial animals in comparison to those in the marine realm.

Methods. We used the fly Drosophila melanogaster to study the effects that exposure to plastics may have on life history traits and immune response. We reared flies in four conditions: In media containing $1 \%$ virgin polyethylene, with no chemical additives; in media supplemented with $1 \%$ or $4 \%$ polyvinyl chloride, known to have a high content of added chemicals; and control flies in non-supplemented media. Plastic particle size ranged from 23-500 $\mu \mathrm{m}$. We studied fly survival to viral infection, the length of the larval and pupal stage, sex ratios, fertility and the size of the resultant adult flies. We then performed crossings of F1 flies in non-supplemented media and looked at the life history traits of the F2.

Results. Flies treated with plastics in the food media showed changes in fertility and sex ratio, but showed no differences in developmental times, adult size or the capacity to fight infections in comparison with controls. However, the offspring of treated flies reared in nonsupplemented food had shorter life cycles, and those coming from both polyvinyl chloride treatments were smaller than those offspring of controls.

Introduction

Plastics are found ubiquitously contaminating aquatic and terrestrial systems, but we still know little of their effects on health. Microplastics (plastic particles less than $5 \mathrm{~mm}$, either manufactured, created by weathering of larger plastic fragments or fibers from clothing items 
(Andrady, 2011; Browne et al., 2011)), represent the overwhelming majority of the total plastic

39

40

41

42

43

44

45

46

47

48

49

50

51

52

53

54

55

56

57

58

59

60

61

62

63

64

65

66

67

68

69

70

71

72

73

74

75

76

77

78

79 in the sea (Cozar et al., 2014; Eriksen et al., 2014). However, microplastics are also being recovered from freshwater settings (reviewed in (Eerkes-Medrano, Thompson \& Aldridge, 2015)), from lake systems (Driedger et al., 2015) to mountain catchments (Allen et al., 2019), as well as in terrestrial environments (Rillig, 2012; de Souza Machado et al., 2018).

Although lagging behind the work on marine organisms (Bergmann, Gutow \& Klages, 2015; Martínez-Gómez et al., 2017b; Rendell-Bhatti et al., 2020), there is growing evidence for impacts on terrestrial animals. Several studies found birds to have ingested microplastics, either directly or via trophic transfer (Holland, Mallory \& Shutler, 2016; Zhao, Zhu \& Li, 2016), and earthworm growth rate was reduced and mortality increased when exposed to $<150 \mu \mathrm{m}$ polyethylene (PE) microplastic particles (Huerta Lwanga et al., 2016). While not affecting its life cycle, the moth Bombyx mori shows behavioural alterations when treated with polystyrene (PS) nanoplastics (Parenti et al., 2020). Aquatic mosquito larvae have been found to be able to eat $2 \mu \mathrm{m}$ PS beads and transfer them to the adult terrestrial life stage (Al-Jaibachi, Cuthbert \& Callaghan, 2018). Other diptera have been exposed to dietary plastics. The life traits of the midge Chironomus riparius were affected by $20-100 \mu \mathrm{m}$ mixed-polymer plastic microparticles, in particular larval body mass increased and there were changes in the shapes of larval mouth parts and female wings in treated animals (Stanković et al., 2020). In the same organism, on the contrary, another study found that 32-500 $\mu \mathrm{m}$ PE particle exposure reduced larval size, as well as delaying development (Silva et al., 2019). In the soil arthropod Folsomia candida, ingestion of 1-63 $\mu \mathrm{m}$ PE microplastic beads is linked to behavioural changes, with reduced velocity and distance of movement (Kim \& An, 2020). Movement was also impaired by 0.1-1 $\mu \mathrm{m}$ PS microbead ingestion in Drosophila melanogaster (Zhang et al., 2020).

Despite this growing body of literature demonstrating negative effects, the specific effects of plastic exposure on health outcomes remain almost completely unknown (Campanale et al., 2020; Hirt \& Body-Malapel, 2020). Exposure to different types and sizes of plastics has been known to modulate the immune system as shown by altered gene expression (producing stress and immune related proteins) in aquatic animals such as molluscs (Mytilus galloprovincialis exposed to either $3 \mu \mathrm{m}$ PS or 1-50 $\mu \mathrm{m}$ PE (Capolupo et al., 2018; Détrée \& Gallardo-Escárate, 2018) and fish (Danio rerio exposed to $700 \mathrm{~nm}$ PS beads (Veneman et al., 2017) and Sparus aurata exposed to 40-150 $\mu \mathrm{m}$ polyvinyl chloride (PVC) (Espinosa, Cuesta \& Esteban, 2017)). 130 $\mu \mathrm{m}$ PVC particles increased phagocytic activity of immune cells in the annelid Arenicola marina (Wright et al., 2013)), and PS nano and microparticles increased immune cell counts the crustacean Daphnia magna (Sadler, Brunner \& Plaistow, 2019; Aljaibachi et al., 2020). Moreover, immune inflammatory response was triggered in molluscs ( $80 \mu \mathrm{m}$ PE particles) and fish $(0.5$ and $50 \mu \mathrm{m}$ PS beads) (von Moos, Burkhardt-Holm \& Koehler, 2012; Jin et al., 2018). Other immune reactions have been detected after 250-1000 $\mu \mathrm{m}$ PE particle ingestion in earthworms (Eisenia Andrei) (Rodriguez-Seijo et al., 2017) and in human cell lines exposed to 0.5-100 $\mu \mathrm{m}$ PS beads (Hwang et al., 2020).

How these physiological responses translate to the immune capacity of the animals is not known, but they have been regarded as potential interference with resistance to disease (Greven et al., 2016). The objective of this study was to test the effect of microplastic contamination in the

Peer) reviewing PDF | (2021:01:57060:1:0:NEW 19 Mar 2021) 
80 immune response to viral infection using the amenable model $D$. melanogaster, as well as 81 observing their effect in the life cycle of the flies which was not previously known.

\section{Materials and Methods}

83 Plastic particles.

84 Polyethylene (PE) particles were obtained by grinding commercial PE nurdles (Merck, catalogue

85

86

87

88

89

90

91

92

93

94

95

96

97

98

99

100

101

102

103

104

105

106

107

108

109

110

111

112

113

114

115

116

117

118

119 number 428043). Polyvinyl Chloride (PVC) particles were obtained by grinding commercial white PVC prime virgin plasticised pellets kindly provided by Northern Polymers and Plastics Ltd. (UK). PE nurdles are virgin (additive-free) particles, while PVC are plasticised pellets with potentially high levels of hazardous chemical additives such as phthalates (Navarro et al., 2010) and polyaromatic hydrocarbons (Rendell-Bhatti et al., 2020). Both pellets were ground using a SPEX Sample Prep Freezer/Mill 6870 cryogrinder using 4 cycles of two minute runs at 15 beats per second with a cooling time of 2 minutes between cycles. Both types of nurdles had similar mechanical properties in grinding. Fragments were sieved through 500, 250, 125 and $23 \mu \mathrm{m}$ meshes, and a mixture was assembled (10\% of $250-500 \mu \mathrm{m}$ particles, $80 \%$ of $125-250 \mu \mathrm{m}$ and 10\% 23-125 $\mu \mathrm{m})$. Microplastic particles were added to Drosophila melanogaster cornmeal media at either 1\% PE, 1\% PVC or 4\% PVC (weight/volume, w/v) in the F1 only. Controls were reared in non-supplemented cornmeal media, as were all flies in the F2. Cornmeal media recipe and nutritional information is provided in the supplementary materials (Supplementary table 1).

F1 matings

D. melanogaster mating cages were set up with apple juice 3\% agar plates where females laid enough eggs to obtain the desired large amount of synchronous embryos. All embryos were pooled together and suspended in water. $10 \mu \mathrm{l}$ embryo squirts were added to each vial, alternating conditions so one vial of each condition was prepared each time, for a total of 30 vials per treatment. Embryo squirts allow a consistently similar number of embryos to be added in each vial. Flies were left to develop at $25^{\circ} \mathrm{C}, 12 \mathrm{~h}: 12 \mathrm{~h}$ day night cycle, $70 \%$ humidity.

F1 life history measurements

30 tubes for each control, 1\%PVC and 1\%PE treatments were used to study pupation and eclosion times. For each tube, time of pupation of every larva and time of eclosion of every adult was recorded. Offspring of every treatment were pooled to determine the ratio of males and females. For experimental set-up reasons, as we could not obtain 30 tubes for this condition, 4\% PVC was not used to study developmental times or sex ratio. 4\% PVC was however used for viral experiments and size measurements, as well as to set up matings to study fertility and F2 life history.

\section{F2 matings}

To be able to assess fertility of the exposed flies, 3-day old female and male flies for each treatment obtained from the life cycle experiment were crossed at a ratio one female to two males per vial, in 20 vials. Food supplied was cornmeal media with no addition of plastic particles, and rearing conditions were $25^{\circ} \mathrm{C}, 12 \mathrm{~h}: 12 \mathrm{~h}$ day night cycle, $70 \%$ humidity. After 30 hours, males were removed. Females were changed to a new vial every three days, up to day 
12015 , when the female was discarded from the last tube. This way, five tubes with offspring were

121 obtained for each female, unless she died before the end of this period.

122 F2 life history measurements

123 For each vial, we recorded time of first pupation and of first adult eclosion. Each tube was kept

124 for 8 days after the first adult emerged to allow eclosion of all pupae. At day 8 , all adult flies

125 from that tube were counted, discerning between males and females. Adult size, total number

126 of flies obtained per female, as well as ratio of male and female, and total number of flies

127 obtained per treatment were investigated.

128 Size

129 Adult size was approximated by wing length (Sharma, Tregenza \& Hosken, 2011) for F1 and F2

130 flies. Adults were kept in ethanol until both wings of 30 males for each treatment were

131 dissected, flat mounted on a slide and measured under a Leica DM IL LED microscope using the

132 LAS X software to undertake measurements.

133 Infection survival

134 Virus infection survival experiments were performed on 60 F1 males of the same age for each treatment. Due to logistical constraints, only the F1 was subject to infection. Viral treatments included non-injected males (control), control injected males (sterile challenge with Ringer's solution) and virus injected males (viral challenge) for each media treatment (control, PE 1\%, PVC $1 \%$ and PVC 4\%). Males were kept in groups of ten. Two-day old flies were anesthetized on $\mathrm{CO}_{2}$ and inoculated using a $0.0125 \mathrm{~mm}$ diameter stainless steel needle that was bent to a right angle ca. $0.25 \mathrm{~mm}$ from the end (Fine Science Tools, CA, USA). The bent tip of the needle was dipped into the Drosophila C virus (DCV) strain B6A $\left(\right.$ TCID50 $\left.=6.32 \times 10^{9}\right)$ which is derived from an isolate collected from D. melanogaster in Charolles, France (Jousset et al., 1972). At the dose used, $100 \%$ of the flies are successfully infected (Longdon et al., 2013). Flies were inoculated through the pleural suture on the thorax (Longdon et al., 2018). We selected this route of infection as oral inoculation has been shown to lead to stochastic infection outcomes in $D$. melanogaster. However, once the virus passes through the gut barrier, both oral and pinpricked infections follow a similar course, with both resulting in the same tissues becoming infected with DCV (Cherry \& Perrimon, 2004; Arnold, Johnson \& White, 2013; Ferreira et al., 2014; Chtarbanova et al., 2014). Infection of DCV by inoculation is highly pathogenic in adult D. melanogaster, causing increased mortality, metabolic and behavioural changes and nutritional stress in the intestine, producing similar pathologies to starvation (Christian, 1987; Arnold, Johnson \& White, 2013; Chtarbanova et al., 2014; Vale \& Jardine, 2017). Survival was recorded daily until all infected animals had died.

Statistical analysis

To determine whether the different media treatments caused a significant effect on adult size and larval and pupal stages duration we applied a Kruskal-Wallis analysis of the variance because data normality and homoscedasticity were not met. The multiple comparison Dunn's test was employed to determine the cases with significant differences $(P<0.05)$. All tests were performed using the R software, version 3.5.1 (R Core Team, 2019). 
160 To assess whether plastic exposure affected female fertility in the F1, we applied a generalized

161 linear model with zero-inflated negative binomial distribution (log link function), using total

162 adult offspring as response variable and plastic treatment as fixed effect. We then used a Tukey

163 test to perform multiple pairwise comparisons between treatments.

164 To evaluate how a rearing environment containing plastics influenced the ability of the resulting 165 adults to resist an immune challenge with a viral pathogen (DCV), we used a parametric survival 166 analysis (the survreg function in R (Therneau, 1999)). The maximal model included, the 167 response variable of the number of days that each individual survived after the viral challenge, 168 control sham infection or non-challenged was administered, any individuals who survived 169 beyond 22 days were censored and recorded as such. The fixed effects included the plastic 170 treatment, the viral treatment and the replicate. The Weibull distribution was used for analysis 171 as it showed the best fit with minimum error deviance. There was no effect of replicate in the 172 maximal model $(\chi 2=1361.14, d f=1361, p=0.94)$, and was removed from further analysis.

173 Results

174 Virus resistance

175 In order to determine if plastic elicits an effect on the ability of flies to resist viral infection, we

176

177 performed a viral resistance assay across individuals that had been reared on each of the plastic treatments. The survival of virally challenged adult flies was compared to those that were sham challenged with a virus free inoculation ('sterile control') and those that were completely naïve

179

180 ('unchallenged control'). After two weeks, most virus-injected flies had died across all treatments, while most non-injected and blank-injected flies were alive (Figure 1). To observe if there was an effect of plastic treatment we looked at the interaction between the viral treatment and plastic rearing environment, which appeared to be non-significant (Viral Treatment $x$ Plastics: $\chi 2=10.55, \mathrm{df}=710, \mathrm{p}=0.103$ ). Effect of plastic exposure on D. melanogaster life cycle

185

186

187

188

189

190

191

192

193

194

195

196

197

198

199
We recorded the number of pupae and adults, discerning for male and female adults, for each treatment, as well as the time to pupation and the time of eclosion (in days). Having added the same number of eggs per vial in each treatment (see materials and methods), we obtained 814 pupae and 810 adults for the control treatment. For the PVC treatment we obtained 691 pupae and 672 adults, and for the PE treatment we obtained 691 pupae and 677 adults. There is an asymmetry in the number of animals (pupae and adults) obtained from each treatment; plastic treatments yield 0.85 flies for every fly in the control treatment. However, these differences were non-significant (unpaired $t$-test between treatment pairs). The percentage of adults that emerged from the pupae was equivalent in all treatments, with success rates $99.3 \%$ in the control, $97.8 \%$ in $1 \%$ PE and $97.5 \%$ in $1 \%$ PVC treatments. The time of pupation follows a distribution with a peak of individuals pupating on day 3 , with no significant differences between treatments, and the larval stage duration is similar for all treatments $\left(X^{2}=3.27, p=\right.$ 0.195 , Figure 2 a). The same is seen for the time of eclosion of adults, also with a peak of individuals emerging on day three for all treatments, and pupa duration similar for all treatments $\left(X^{2}=1.73 p=0.421\right.$, Figure $\left.2 \mathrm{~b}\right)$. 
200 We also looked at the stage duration of larvae and pupae in the F2, where flies were reared 201 from treated flies in non-treated food. In this case, offspring of 4\% PVC treated flies (not

202 included in the F1 life cycle experiments) had shorter larval stages $\left(X^{2}=43.41, p=2 e-09\right.$, Figure

$2032 \mathrm{c})$, and offspring of all plastic treatments had shorter pupal stages than the control $\left(X^{2}=\right.$

204 11.31, $p=0.01$, Figure $2 d$ ).

205 We looked at the fertility per female in the F1 (see materials and methods). We found that

206

207

208

209

210

211

212

213

214

215

216

217

218

219

220

221

222

223

224

225

226

227

228

229

230

231

232

233

234

235

236

237

238

239 females reared with 1\% PE laid more eggs than the controls, and those reared with 4\% PVC laid marginally more eggs than the control (difference among all groups $X^{2}=14.4, p=0.002$, Figure 3 ). We saw no differences between 1\% PVC treatments and controls.

The total number of females and males obtained for each treatment was recorded (Supplementary Table 2). In the F1, while in the control treatment there was near equivalence (50.2\% males), in the plastic treatments there was a slight decrease in the proportion of males. A binomial test indicated that the proportion of males of $46.4 \%$ for $1 \%$ PE and $44.5 \%$ for $1 \%$ PVC were lower than the expected $50 \%(p=0.03$ and $p=0.002$, respectively (1-tailed)). In the $F 2$, were larvae obtained from the treated animals were fed with food with no additives, however, we saw no differences and sex ratios were at near equivalence in all treatments.

Adult fly size

Size of male flies resulting from larvae exposed to the different treatments was measured, as well as F2 male flies not exposed to additives in their food. F1 males from exposed larvae did not show any significant size differences between treatments and controls $\left(X^{2}=2.47, p=0.480\right.$ Figure 4 a). However, when the F2 individuals were measured, adults in both $1 \%$ and $4 \%$ PVC treatments were significantly smaller than the controls and $1 \%$ PE treatments $\left(X^{2}=14.78, p=\right.$ 0.002, Figure 4 b).

\section{Discussion}

Drosophila melanogaster has been used in many toxicological studies and recently has been utilised as a tool for the rapid assessment of microplastic mediated toxicity (Zhang et al., 2020). Here we used $D$. melanogaster to assess the toxicity of two types of plastic: virgin microplastic with no added chemicals (PE) and industrial plastics known to have hazardous chemical additives (PVC). Leachates of the PVC particles used in this study have been shown to disrupt sea urchin development and to contain harmful chemicals that can be released into sea water (Rendell-Bhatti et al., 2020). Some plastic additives have been linked to changes in developmental time, size and fitness in D. melanogaster (Quesada-Calderón et al., 2017; Chen et al., 2019). In the current study, the plastics were added to a semisolid food matrix, and we did not study the possible release of chemicals from the plastics to the food. Although we were not able to test if the larvae had ingested the added plastics, the particle sizes were small enough to be eaten by later instar larvae, though they may have selectively chosen to avoid eating them. However, we saw the strongest effects in the offspring of flies treated with higher percentage of plastics and those known to have chemicals adsorbed, and we therefore hypothesise that the effects we saw may be caused by both these factors: a higher concentration of particles and higher amount of chemical additives. 
240 It is important to note that particle size is important for the strength of any plastic effects (Lee

241

242

243

244

245

246

247

248

249

250

251

252

253

254

255

256

257

258

259

260

261

262

263

264

265

266

267

268

269

270

271

272

273

274

275

276

277

278

279

280

281 et al., 2013; Haegerbaeumer et al., 2019; Silva et al., 2019). Using round 1 and $0.1 \mu \mathrm{m}$ polystyrene beads, a study in D. melanogaster found gut damage and locomotion disfunction, amongst other effects (Zhang et al., 2020). Our study used a more environmentally relevant plastic model: plastic fragments of irregular shape and sizes ranging from 23 to $500 \mu \mathrm{m}$. Despite larger irregular particles being more likely to be found in the environment than nanobeads, these may be less readily available to be ingested by the larvae. The particles used in two studies on C. riparius had a similar size to those used in our study (Silva et al., 2019; Stanković et al., 2020). Other studies had used environmentally relevant concentrations of plastics in riverine sediments to a concentration of $0.04 \%$ (weight in volume) (Stanković et al., 2020), 25 times lower than the concentration used in our $1 \%$ treatments. However, our study provides an account of what can happen in the case of food being taken from highly contaminated sites, which are now widespread. The concentration of plastics added to the food in this study, although high ( 1 or $4 \%$ weight in volume), is a plausible representation of such sites. This is the case in landfill sites and other highly polluted settings. (municipal solid waste sent to landfills in America contained $18.5 \%$ of plastics (United States Environment Protection Agency, 2020)), where a wide variety of insects live off food items mixed with plastic and other inedible materials (Qasim et al., 2020).

Our study showed no effect of the plastic treatments in the capacity to fight viral infections in D. melanogaster. Previous studies had reported effects in the immune system of several models by increase of immune cell numbers, physiological changes or protein or gene overexpression (Canesi et al., 2015; Balbi et al., 2016; Greven et al., 2016; Sadler, Brunner \& Plaistow, 2019; Hirt \& Body-Malapel, 2020). Other studies found injection of latex beads (composed of polystyrene) used to block phagocytosis (Elrod-Erickson, Mishra \& Schneider, 2000) can increase susceptibility to some pathogens (Costa et al., 2009; Lamiable et al., 2016). To the best of our knowledge, this is the first report testing the outcome of viral infection after microplastic exposure. Despite our results showing no decrease in the capacity to resist viral infection in plastic treated flies, we could not rule out a transgenerational immune effect, or an additive effect after exposure for several generations, as it happens in other systems for exposures to toxicants such as heavy metals (blow fly, (Pölkki, Kangassalo \& Rantala, 2012)) or bisphenol S (mouse, (Brulport et al., 2021). Further experiments with a fully-factorial design should be considered to shed light on this point.

We observed significant differences in the male/female ratio in the 1\% PE and 1\% PVC treatments in the F1. In contrast, no differences in sex ratios were found in C. riparius treated with PE particles of equivalent size to the ones used in this study (Silva et al., 2019). Since plastic additives often include endocrine disruptors, which are also known to affect $D$. melanogaster (Quesada-Calderón et al., 2017; Chen et al., 2019), we initially hypothesised that the male/female ratio could be affected by chemical additives in the PVC treatments. However, we also found an effect in the PE treatment, which had no added chemicals, and hence released chemicals may not be the only factor contributing to this effect. Nevertheless, we take this result with caution as the pooling of all vials from each treatment to classify offspring by sex may have confounded the results, as we could not control for vial effects.

Peer) reviewing PDF | (2021:01:57060:1:0:NEW 19 Mar 2021) 
282 We saw confounding changes in the fertility of treated flies. Both $1 \%$ PE and to a lesser extent $2834 \%$ PVC treatments had more offspring than the control but the 1\% PVC treatment showed no 284 differences with the control. Similar confounding results were seen in D. magna, where 285 exposure to 1-5 $\mu \mathrm{m}$ spheres reduced fertility in successive generations after microplastic 286 exposure (Martins \& Guilhermino, 2018), but animals exposed to $0.5 \mu \mathrm{m}$ PS beads showed 287 significant grater clutch sizes (Sadler, Brunner \& Plaistow, 2019). These results were linked to 288 microplastic induced physical effects and chemical toxicity for the reduction in fertility, and 289 upregulation of haemocytes (immune response) in the case of the increased fertility. Future 290 work could inform whether these mechanisms are also responsible for the effects we saw in 291 our case.

292 We saw no effect in developmental time or adult size in the D. melanogaster exposed to 293 microplastics. In the dipteran Chironomus riparius exposure to mixed microplastics 294 (polyethylene-terephthalate, polystyrene, PVC and polyamide) resulted in increased average 295 body mass and length, as well as a significant increase of the development time from first instar 296 to adult (Stanković et al., 2020). In contrast, ingestion of polyethylene by the same dipteran $C$. 297 riparius, produced conflicting results showing reduced larval growth, but also a delay in the 298 emergence of adults (Silva et al., 2019). It is unclear why all these results differ but it could be 299 down to the aquatic medium in which $C$. riparius was exposed or due to the different properties 300 of the microplastic or microplastic mixes used.

301 Despite not seeing timing or size effects in the F1 generation of $D$. melanogaster, we saw 302 differences in the offspring of treated flies: the size of the F2 adults in PVC treatments (at both 303 concentrations tested) were smaller than control animals, and the life cycle was shorter in the 304 offspring of all treated flies. Similar results have been seen in the aquatic model Daphnia 305 magna, where individuals exposed to microplastics had smaller offspring but no other changes 306 in life history traits. This change in D. magna was linked to increased numbers of immune cells 307 under microplastic exposure (Sadler, Brunner \& Plaistow, 2019). In our case, the flies were not 308 exposed to plastics, but were the offspring of exposed flies. In D. melanogaster and other flies, 309 the size of pupae and adult flies depends on the size of the larvae at the moment of pupation, 310 which is determined by the availability of food during larval development. Starvation usually 311 correlates with a longer larval stage, to attain the minimal viable size to survive metamorphosis, 312 and a shorter pupal stage, probably since smaller larvae means less tissue to be 313 metamorphosed (Alcaine-Colet, Wotton \& Jimenez-Guri, 2015). In our case, the affected flies 314 were reared in plastic-free media, and therefore we did not expect that the food source would 315 trigger a change in their body size and developmental time. The changes to smaller size and 316 shorter life cycles in the F2 generation could be due to many potential factors such as an 317 epigenetic effect in the F1 which affects the F2, or a condition effect in the mothers, such as 318 physiological toxicity caused by physical effects (for example mechanical damage to the gut of 319 the mother) or chemical toxicity, that affects offspring development. Plastic particles are known 320 to cause oxidative stress (reviewed in (Pérez-Albaladejo, Solé \& Porte, 2020)), neurotoxicity 321 (reviewed in (Prüst, Meijer \& Westerink, 2020)) and developmental toxicity in other animals 322 (Martínez-Gómez et al., 2017a; Messinetti et al., 2018; Rendell-Bhatti et al., 2020), as well as 323 reduced gut function (Wright et al., 2013), which may have a negative knock on effect in 324 subsequent generations. In favour of this hypothesis, we saw that the offspring of flies with the 
325 higher dose of plastics (4\% PVC), which also are known to contain harmful chemicals (Rendell326 Bhatti et al., 2020), were the ones showing both the strongest changes in their life cycles, with 327 shorter larval and pupal stages, and the greatest reduction in body size.

\section{Conclusions}

329 Exposure to microplastic particles affects sex ratios and fecundity in $D$. melanogaster within 330 exposed generation, but does not significantly change its life cycle nor affect the ability of male

331

332

333

334

335

336

337

338

339

340

341

342

343

344

345

346

347

348

349

350

351

352

353

354

355

356

357

358

359

360

361

362

363

flies to fight viral infection. However, non-exposed offspring of exposed flies from higher content (4\% w/v) PVC show a shorter larval stage compared to all other treatments and controls, and non-exposed offspring from exposed flies of all plastic treatments show a decrease in the duration of the pupa stage. Despite flies reared in supplemented food showing no differences in body size, non-exposed offspring of exposed flies from PVC treatments show a significant decrease in body size with respect to all other treatments. We saw the strongest effects in the non-exposed offspring of flies treated with higher percentage of plastics and those known to have chemicals adsorbed. Further investigation is needed into the effect of our increasingly plastic-contaminated terrestrial environments on life history traits of exposed animals.

\section{Acknowledgments}

We thank Dave Hosken, MD Sharma and Keiko Oku for support with the F2 fertility experimental set up, Tamara Galloway and Adam Porter for access to and help with plastic grinding facilities, Flora Rendell-Bhatti for help with plastic grinding, Karl R Wotton for the use of microscope equipment and critically reading the manuscript, and Pablo Capilla-Lasheras for help with an earlier version of the work. The manuscript benefitted from the constructive review of three anonymous reviewers and the Editor.

\section{Bibliography}

Al-Jaibachi R, Cuthbert RN, Callaghan A. 2018. Up and away: Ontogenic transference as a pathway for aerial dispersal of microplastics. Biology Letters 14. DOI: 10.1098/rsbl.2018.0479.

Alcaine-Colet A, Wotton KR, Jimenez-Guri E. 2015. Rearing the scuttle fly Megaselia scalaris (Diptera: Phoridae) on industrial compounds: implications on size and lifespan. PeerJ 3:e1085. DOI: 10.7717/peerj.1085.

Aljaibachi R, Laird WB, Stevens F, Callaghan A. 2020. Impacts of polystyrene microplastics on Daphnia magna: A laboratory and a mesocosm study. Science of the Total Environment 705. DOI: 10.1016/j.scitotenv.2019.135800.

Allen S, Allen D, Phoenix VR, Le Roux G, Durántez Jiménez P, Simonneau A, Binet S, Galop D. 2019. Atmospheric transport and deposition of microplastics in a remote mountain catchment. Nature Geoscience 12:339-344. DOI: 10.1038/s41561-019-0335-5.

Andrady AL. 2011. Microplastics in the marine environment. Marine Pollution Bulletin 62:15961605. DOI: 10.1016/j.marpolbul.2011.05.030.

Arnold PA, Johnson KN, White CR. 2013. Physiological and metabolic consequences of viral

Peer] reviewing PDF | (2021:01:57060:1:0:NEW 19 Mar 2021) 
364

365

366

367

368

369

370

371

372

373

374

375

376

377

378

379

380

381

382

383

384

385

386

387

388

389

390

391

392

393

394

395

396

397

398

399

400

401

infection in Drosophila melanogaster. Journal of Experimental Biology 216:3350-3357. DOI: $10.1242 /$ jeb.088138.

Balbi T, Franzellitti S, Fabbri R, Montagna M, Fabbri E, Canesi L. 2016. Impact of bisphenol A (BPA) on early embryo development in the marine mussel Mytilus galloprovincialis : Effects on gene transcription. Environmental Pollution 218:996-1004. DOI: 10.1016/j.envpol.2016.08.050.

Bergmann M, Gutow L, Klages M. 2015. Marine anthropogenic litter. Marine Anthropogenic Litter:1-447. DOI: 10.1007/978-3-319-16510-3.

Browne MA, Crump P, Niven SJ, Teuten E, Tonkin A, Galloway T, Thompson R. 2011. Accumulation of Microplastic on Shorelines Woldwide: Sources and Sinks. Environmental Science \& Technology 45:9175-9179. DOI: 10.1021/es201811s.

Brulport A, Lencina C, Chagnon MC, Le Corre L, Guzylack-Piriou L. 2021. Transgenerational effects on intestinal inflammation status in mice perinatally exposed to bisphenol $\mathrm{S}$. Chemosphere 262:0-8. DOI: 10.1016/j.chemosphere.2020.128009.

Campanale C, Massarelli C, Savino I, Locaputo V, Uricchio VF. 2020. A detailed review study on potential effects of microplastics and additives of concern on human health. International Journal of Environmental Research and Public Health 17. DOI: 10.3390/ijerph17041212.

Canesi L, Ciacci C, Bergami E, Monopoli MP, Dawson KA, Papa S, Canonico B, Corsi I. 2015. Evidence for immunomodulation and apoptotic processes induced by cationic polystyrene nanoparticles in the hemocytes of the marine bivalve Mytilus. Marine Environmental Research 111:34-40. DOI: 10.1016/j.marenvres.2015.06.008.

Capolupo M, Franzellitti S, Valbonesi P, Lanzas CS, Fabbri E. 2018. Uptake and transcriptional effects of polystyrene microplastics in larval stages of the Mediterranean mussel Mytilus galloprovincialis. Environmental Pollution 241:1038-1047. DOI: 10.1016/j.envpol.2018.06.035.

Chen MY, Liu HP, Cheng J, Chiang SY, Liao WP, Lin WY. 2019. Transgenerational impact of DEHP on body weight of Drosophila. Chemosphere 221:493-499. DOI: 10.1016/j.chemosphere.2018.12.193.

Cherry S, Perrimon N. 2004. Entry is a rate-limiting step for viral infection in a Drosophila melanogaster model of pathogenesis. Nature Immunology 5:81-87. DOI: 10.1038/ni1019.

Christian PD. 1987. Studies on Drosophila C and A viruses in Australian populations of Drosophila melanogaster.

Chtarbanova S, Lamiable O, Lee K-Z, Galiana D, Troxler L, Meignin C, Hetru C, Hoffmann JA, Daeffler L, Imler J-L. 2014. Drosophila C Virus Systemic Infection Leads to Intestinal Obstruction. Journal of Virology 88:14057-14069. DOI: 10.1128/jvi.02320-14.

Costa A, Jan E, Sarnow P, Schneider D. 2009. The Imd pathway is involved in antiviral immune responses in Drosophila. PLOS ONE 4. DOI: 10.1371/journal.pone.0007436.

Cozar A, Echevarria F, Gonzalez-Gordillo JI, Irigoien X, Ubeda B, Hernandez-Leon S, Palma AT, 
402

403

404

405

406

407

408

409

410

411

412

413

414

415

416

417

418

419

420

421

422

423

424

425

426

427

428

429

430

431

432

433

434

435

436

437

438

439

440

Navarro S, Garcia-de-Lomas J, Ruiz A, Fernandez-de-Puelles ML, Duarte CM. 2014. Plastic debris in the open ocean. Proceedings of the National Academy of Sciences 111:1023910244. DOI: 10.1073/pnas.1314705111.

Détrée C, Gallardo-Escárate C. 2018. Single and repetitive microplastics exposures induce immune system modulation and homeostasis alteration in the edible mussel Mytilus galloprovincialis. Fish and Shellfish Immunology 83:52-60. DOI: 10.1016/j.fsi.2018.09.018.

Driedger AGJ, Dürr HH, Mitchell K, Van Cappellen P. 2015. Plastic debris in the Laurentian Great Lakes: A review. Journal of Great Lakes Research 41:9-19. DOI: 10.1016/j.jglr.2014.12.020.

Eerkes-Medrano D, Thompson RC, Aldridge DC. 2015. Microplastics in freshwater systems: A review of the emerging threats, identification of knowledge gaps and prioritisation of research needs. Water Research 75:63-82. DOI: 10.1016/j.watres.2015.02.012.

Elrod-Erickson M, Mishra S, Schneider D. 2000. Interactions between the cellular and humoral immune responses in Drosophila. Current Biology 10:781-784. DOI: 10.1016/S09609822(00)00569-8.

Eriksen M, Lebreton LCM, Carson HS, Thiel M, Moore CJ, Borerro JC, Galgani F, Ryan PG, Reisser J. 2014. Plastic Pollution in the World's Oceans: More than 5 Trillion Plastic Pieces Weighing over 250,000 Tons Afloat at Sea. PLoS ONE 9:1-15. DOI: 10.1371/journal.pone.0111913.

Espinosa C, Cuesta A, Esteban MÁ. 2017. Effects of dietary polyvinylchloride microparticles on general health, immune status and expression of several genes related to stress in gilthead seabream (Sparus aurata L.). Fish and Shellfish Immunology 68:251-259. DOI: 10.1016/j.fsi.2017.07.006.

Ferreira ÁG, Naylor H, Esteves SS, Pais IS, Martins NE, Teixeira L. 2014. The Toll-Dorsal Pathway Is Required for Resistance to Viral Oral Infection in Drosophila. PLoS Pathogens 10. DOI: 10.1371/journal.ppat.1004507.

Greven A-C, Merk T, Karagöz F, Mohr K, Klapper M, Jovanović B, Palić D. 2016. Polycarbonate and polystyrene nanoplastic particles act as stressors to the innate immune system of fathead minnow ( Pimephales promelas ). Environmental Toxicology and Chemistry 35:3093-3100. DOI: 10.1002/etc.3501.

Haegerbaeumer A, Mueller MT, Fueser H, Traunspurger W. 2019. Impacts of micro- and nanosized plastic particles on benthic invertebrates: A literature review and gap analysis. Frontiers in Environmental Science 7. DOI: 10.3389/fenvs.2019.00017.

Hirt N, Body-Malapel M. 2020. Immunotoxicity and intestinal effects of nano- and microplastics: a review of the literature. Particle and Fibre Toxicology 17:1-22. DOI: 10.1186/s12989-02000387-7.

Holland ER, Mallory ML, Shutler D. 2016. Plastics and other anthropogenic debris in freshwater birds from Canada. Science of the Total Environment 571:251-258. DOI: 10.1016/j.scitotenv.2016.07.158.

Huerta Lwanga E, Gertsen H, Gooren H, Peters P, Salánki T, Van Der Ploeg M, Besseling E, 
441

461

462

463

464

465

466

467

468

469

470

471

472

473

474

475

476

477

478
Koelmans AA, Geissen V. 2016. Microplastics in the Terrestrial Ecosystem: Implications for Lumbricus terrestris (Oligochaeta, Lumbricidae). Environmental Science and Technology 50:2685-2691. DOI: 10.1021/acs.est.5b05478.

Hwang J, Choi D, Han S, Jung SY, Choi J, Hong J. 2020. Potential toxicity of polystyrene microplastic particles. Scientific Reports 10:1-12. DOI: 10.1038/s41598-020-64464-9.

Jin Y, Xia J, Pan Z, Yang J, Wang W, Fu Z. 2018. Polystyrene microplastics induce microbiota dysbiosis and inflammation in the gut of adult zebrafish. Environmental Pollution 235:322329. DOI: 10.1016/j.envpol.2017.12.088.

Jousset FX, Plus N, Croizier G, Thomas M. 1972. [Existence in Drosophila of 2 groups of picornavirus with different biological and serological properties]. Comptes rendus hebdomadaires des seances de l'Academie des sciences. Serie D: Sciences naturelles 275:3043-6.

Kim SW, An YJ. 2020. Edible size of polyethylene microplastics and their effects on springtail behavior. Environmental Pollution 266. DOI: 10.1016/j.envpol.2020.115255.

Lamiable O, Arnold J, de Faria IJ da S, Olmo RP, Bergami F, Meignin C, Hoffmann JA, Marques JT, Imler J-L. 2016. Analysis of the Contribution of Hemocytes and Autophagy to Drosophila Antiviral Immunity. Journal of Virology 90:5415-5426. DOI: 10.1128/jvi.00238-16.

Lee K, Shim WJ, Kwon OY, Kang J. 2013. Size-Dependent E ff ects of Micro Polystyrene Particles in the Marine Copepod Tigriopus japonicus. Environmental science \& technology 47:11278-11283. DOI: dx.doi.org/10.1021/es401932b.

Longdon B, Cao C, Martinez J, Jiggins FM. 2013. Previous exposure to an RNA virus does not protect against subsequent infection in Drosophila melanogaster. PloS one 8. DOI: 10.1371/journal.pone.0073833.

Longdon B, Day JP, Alves JM, Smith SCL, Houslay TM, McGonigle JE, Tagliaferri L, Jiggins FM. 2018. Host shifts result in parallel genetic changes when viruses evolve in closely related species. PLoS Pathogens 14:1-14. DOI: 10.1371/journal.ppat.1006951.

Martínez-Gómez C, León VM, Calles S, Gomáriz-Olcina M, Vethaak AD. 2017a. The adverse effects of virgin microplastics on the fertilization and larval development of sea urchins. Marine Environmental Research 130:69-76. DOI: 10.1016/j.marenvres.2017.06.016.

Martínez-Gómez C, León VM, Calles S, Gomáriz-Olcina M, Vethaak AD. 2017b. The adverse effects of virgin microplastics on the fertilization and larval development of sea urchins. Marine Environmental Research 130:69-76. DOI: 10.1016/j.marenvres.2017.06.016.

Martins A, Guilhermino L. 2018. Transgenerational effects and recovery of microplastics exposure in model populations of the freshwater cladoceran Daphnia magna Straus. Science of the Total Environment 631-632:421-428. DOI: 10.1016/j.scitotenv.2018.03.054.

Messinetti S, Mercurio S, Parolini M, Sugni M, Pennati R. 2018. Effects of polystyrene microplastics on early stages of two marine invertebrates with different feeding strategies *. Environmental Pollution 237:1080-1087. DOI: 10.1016/j.envpol.2017.11.030. 
479

480

481

482

483

484

485

486

487

488

489

490

491

492

493

494

495

496

497

498

499

500

501

502

503

504

505

506

507

508

509

510

511

512

513

514

515

516

von Moos N, Burkhardt-Holm P, Koehler A. 2012. Uptake and E ff ects of Microplastics on Cells and Tissue of the Blue Mussel Mytilus edulis L. after an Experimental Exposure. Environmental science \& technology 46:327-335. DOI: 10.1021/es302332w.

Navarro R, Pérez Perrino M, Gómez Tardajos M, Reinecke H. 2010. Phthalate Plasticizers Covalently Bound to PVC: Plasticization with Suppressed Migration. Macromolecules 43:2377-2381. DOI: 10.1021/ma902740t.

Parenti CC, Binelli A, Caccia S, Della Torre C, Magni S, Pirovano G, Casartelli M. 2020. Ingestion and effects of polystyrene nanoparticles in the silkworm Bombyx mori. Chemosphere 257. DOI: 10.1016/j.chemosphere.2020.127203.

Pérez-Albaladejo E, Solé M, Porte C. 2020. Plastics and plastic additives as inducers of oxidative stress. Current Opinion in Toxicology 20-21:69-76. DOI: 10.1016/j.cotox.2020.07.002.

Pölkki M, Kangassalo K, Rantala MJ. 2012. Transgenerational effects of heavy metal pollution on immune defense of the blow fly Protophormia terraenovae. PLOS ONE 7. DOI: 10.1371/journal.pone.0038832.

Prüst M, Meijer J, Westerink RHS. 2020. The plastic brain: Neurotoxicity of micro- And nanoplastics. Particle and Fibre Toxicology 17:1-16. DOI: 10.1186/s12989-020-00358-y.

Qasim M, Xiao H, He K, Noman A, Liu F, Chen MY, Hussain D, Jamal ZA, Li F. 2020. Impact of landfill garbage on insect ecology and human health. Acta Tropica 211:105630. DOI: 10.1016/j.actatropica.2020.105630.

Quesada-Calderón S, Bacigalupe LD, Toro-Vélez AF, Madera-Parra CA, Peña-Varón MR, Cárdenas-Henao H. 2017. The multigenerational effects of water contamination and endocrine disrupting chemicals on the fitness of Drosophila melanogaster. Ecology and Evolution 7:6519-6526. DOI: 10.1002/ece3.3172.

R Core Team. 2019. R: A language and environment for statistical computing. $R$ Foundation for Statistical Computing, Vienna, Austria. Http://Www.r-Project.Org/Index.Html.

Rendell-Bhatti F, Paganos P, Pouch A, Mitchell C, D'Aniello S, Godley BJ, Pazdro K, Arnone MI, Jimenez-Guri E. 2020. Developmental toxicity of plastic leachates on the sea urchin Paracentrotus lividus. Environmental Pollution 269:115744. DOI: 10.1016/j.envpol.2020.115744.

Rillig MC. 2012. Microplastic in terrestrial ecosystems and the soil? Environmental Science and Technology 46:6453-6454. DOI: 10.1021/es302011r.

Rodriguez-Seijo A, Lourenço J, Rocha-Santos TAP, da Costa J, Duarte AC, Vala H, Pereira R. 2017. Histopathological and molecular effects of microplastics in Eisenia andrei Bouché. Environmental Pollution 220:495-503. DOI: 10.1016/j.envpol.2016.09.092.

Sadler DE, Brunner FS, Plaistow SJ. 2019. Temperature and clone-dependent effects of microplastics on immunity and life history in Daphnia magna. Environmental Pollution 255.

Sharma MD, Tregenza T, Hosken DJ. 2011. Sex combs, allometry, and asymmetry in Drosophila. Biological Journal of the Linnean Society 103:923-934. 
517 Silva CJM, Silva ALP, Gravato C, Pestana JLT. 2019. Ingestion of small-sized and irregularly 518 shaped polyethylene microplastics affect Chironomus riparius life-history traits. Science of the Total Environment 672:862-868. DOI: 10.1016/j.scitotenv.2019.04.017.

520

521

522

523

524

525

526

527

528

529

530

531

532

533

534

535

536

537

538

539

540

541

542

543

544

545

546 de Souza Machado AA, Kloas W, Zarfl C, Hempel S, Rillig MC. 2018. Microplastics as an emerging threat to terrestrial ecosystems. Global Change Biology 24:1405-1416. DOI: 10.1111/gcb.14020.

Stanković J, Milošević D, Savić-Zdraković D, Yalçın G, Yildiz D, Beklioğlu M, Jovanović B. 2020. Exposure to a microplastic mixture is altering the life traits and is causing deformities in the non-biting midge Chironomus riparius Meigen (1804). Environmental Pollution 262. DOI: 10.1016/j.envpol.2020.114248.

Therneau TM. 1999. A Package for Survival Analysis in S. :1-83.

United States Environment Protection Agency. 2020. Advancing Sustainable Materials Management: 2018 Fact Sheet.

Vale PF, Jardine MD. 2017. Infection avoidance behavior: Viral exposure reduces the motivation to forage in female Drosophila melanogaster. Fly 11:3-9. DOI: 10.1080/19336934.2016.1207029.

Veneman WJ, Spaink HP, Brun NR, Bosker T, Vijver MG. 2017. Pathway analysis of systemic transcriptome responses to injected polystyrene particles in zebrafish larvae. Aquatic Toxicology 190:112-120. DOI: 10.1016/j.aquatox.2017.06.014.

Wright SL, Rowe D, Thompson RC, Galloway TS. 2013. Microplastic ingestion decreases energy reserves in marine worms. Current Biology 23:R1031-R1033. DOI: 10.1016/j.cub.2013.10.068.

Zhang Y, Wolosker MB, Zhao Y, Ren H, Lemos B. 2020. Exposure to microplastics cause gut damage, locomotor dysfunction, epigenetic silencing, and aggravate cadmium (Cd) toxicity in Drosophila. Science of the Total Environment 744:140979. DOI: 10.1016/j.scitotenv.2020.140979.

Zhao S, Zhu L, Li D. 2016. Microscopic anthropogenic litter in terrestrial birds from Shanghai, China: Not only plastics but also natural fibers. Science of the Total Environment 550:11101115. DOI: 10.1016/j.scitotenv.2016.01.112. 


\section{Figure 1}

Survival of $D$. melanogaster after rearing on food containing plastics and challenged with viral pathogen (DCV).

Survival shows as mean proportion alive per day across the replicates. Red dashed line and circle: control food, yellow crosses and line: $1 \%$ virgin polyethylene (PE) , green line and triangle: $1 \%$ Polyvinyl Chloride (PVC), blue line and triangle: 4\% PVC. Panels are split into the three viral treatments Control- no challenge, Sterile- flies challenged with a sterile infection and Virus- challenged with DCV virus. 


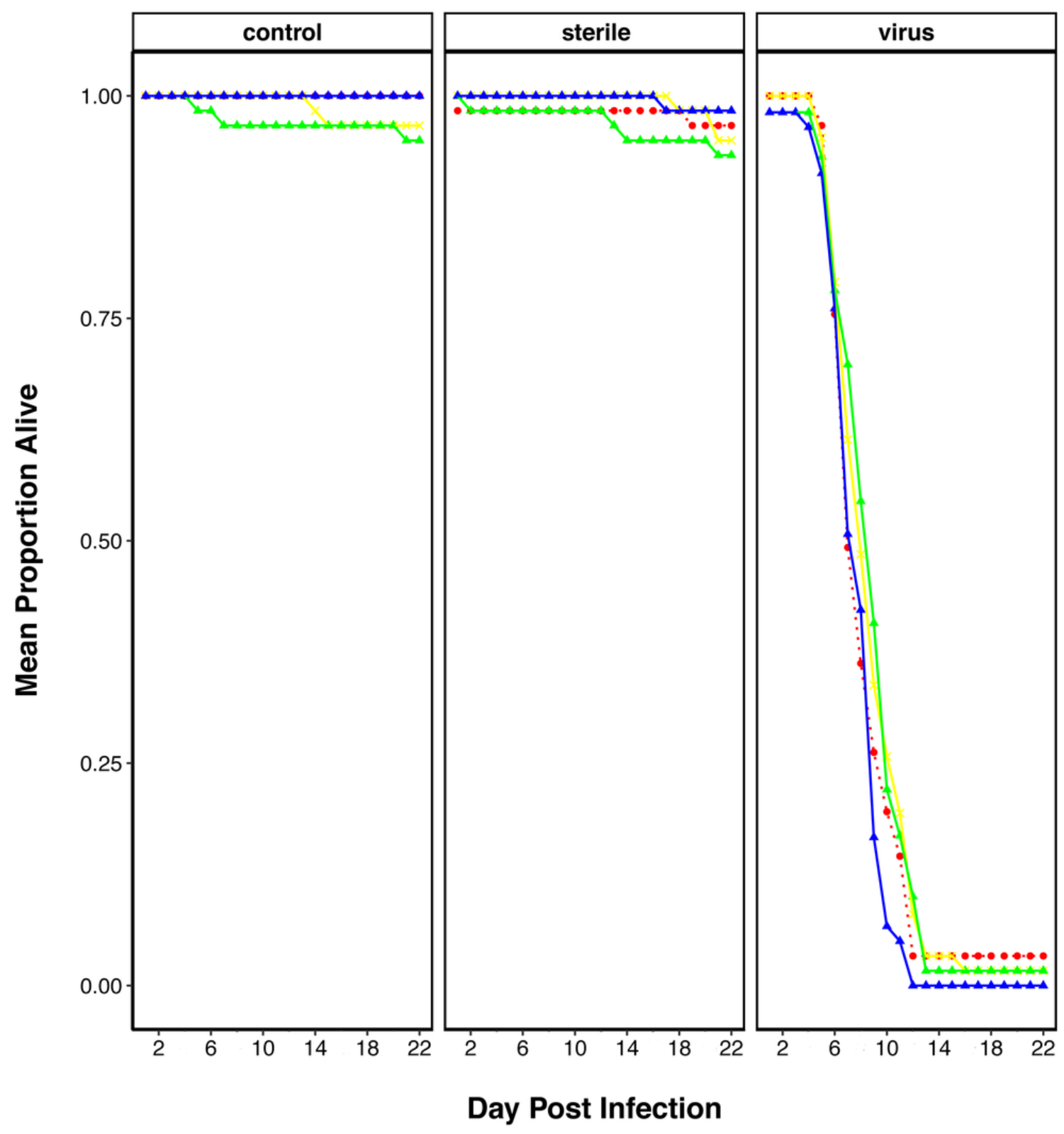




\section{Figure 2}

Stage duration under each condition.

Stage duration in the F1 for (a) larvae and (b) pupa, and in the F2 for (c) larvae and (d) pupa for each treatment. Squares represent the mean and whiskers represent the standard error of the mean (SEM). Red: control, yellow: virgin polyethylene (PE), green: 1\% polyvinyl chloride (PVC), blue: 4\% PVC. Note that $y$ axis extent is different between $a / c$ and $b / d$. Asterisks correspond to significant differences $(p<0.05)$ between the treatment and the control in a multiple comparisons test. 

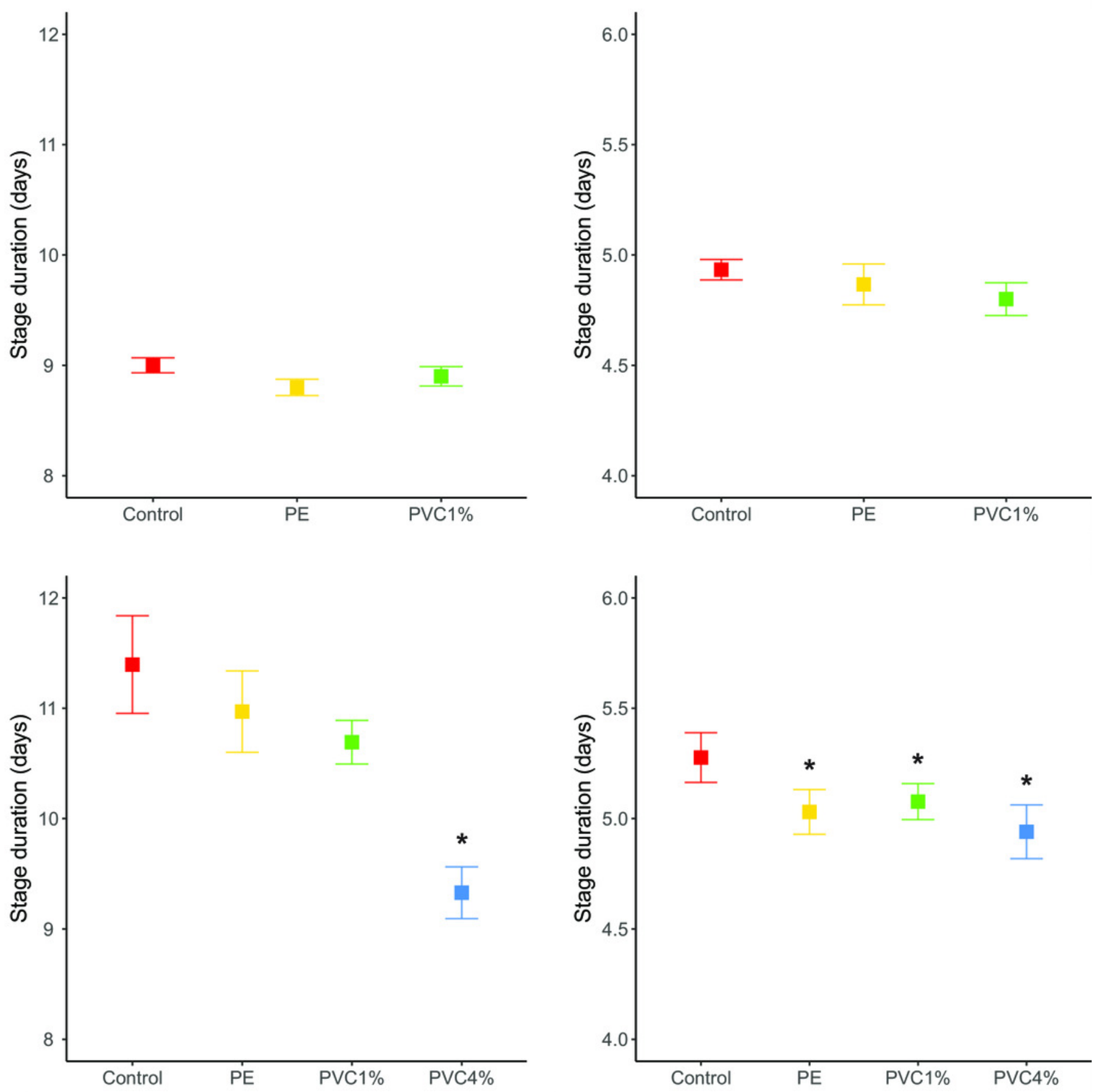


\section{Figure 3}

Offspring per female in the F1

Total offspring per female, where flies reared in plastic supplemented or control media laid eggs on non-supplemented food. Boxes correspond to the interquartile range (IQR), whiskers extend to the largest value no further than $1.5 *$ IQR from the limit of the box, black dots represent the mean, black bars represent the median, and empty dots represent outlier values (exceeding 3 standard deviations from the mean). Profiles at the right of each panel illustrate the distribution density of each treatment. Red box/profile: control, yellow box/profile: $1 \%$ virgin polyethylene (PE), green box/profile: $1 \%$ polyvinyl chloride (PVC), blue box/profile: $4 \%$ PVC. Asterisks correspond to significant differences $(p<0.05)$ between the treatment and the control in a multiple comparisons test. 


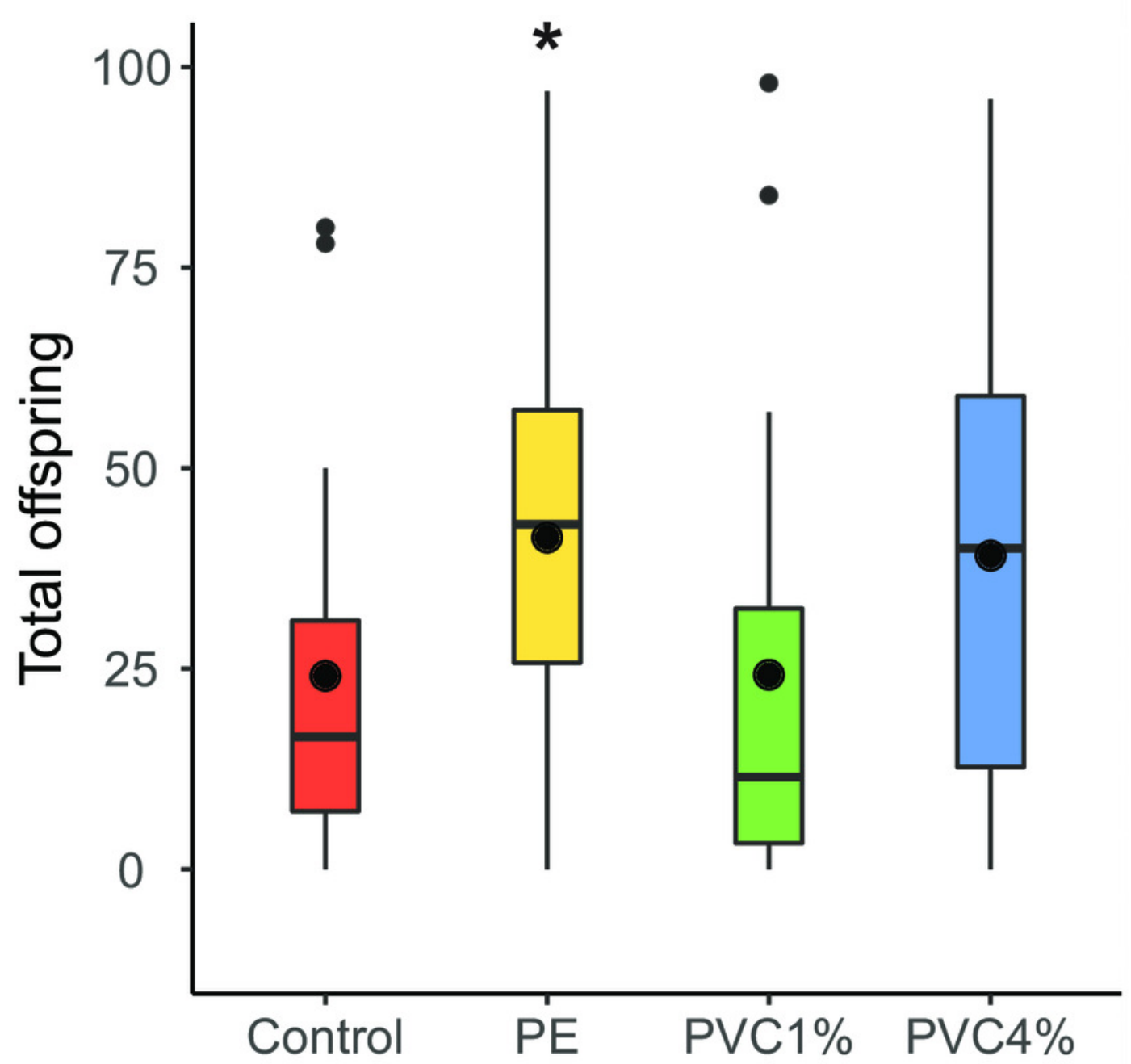




\section{Figure 4}

Comparison of wing size under each condition

Right wing sizes for $\mathrm{F} 1$ (a) and F2 (b) male flies. Boxes correspond to the interquartile range $(I Q R)$, whiskers extend to the largest value no further than $1.5 * I Q R$ from the limit of the box, black dots represent the mean, black bars represent the median, and empty dots represent outlier values (exceeding 3 standard deviations from the mean). Profiles at the right of each panel illustrate the distribution density of each treatment. Red box/profile: control, yellow box/profile: virgin polyethylene (PE), green box/profile: 1\% polyvinyl chloride (PVC), blue box/profile: 4\% PVC. Asterisks correspond to significant differences $(p<0.05)$ between the treatment and the control in a multiple comparisons test.
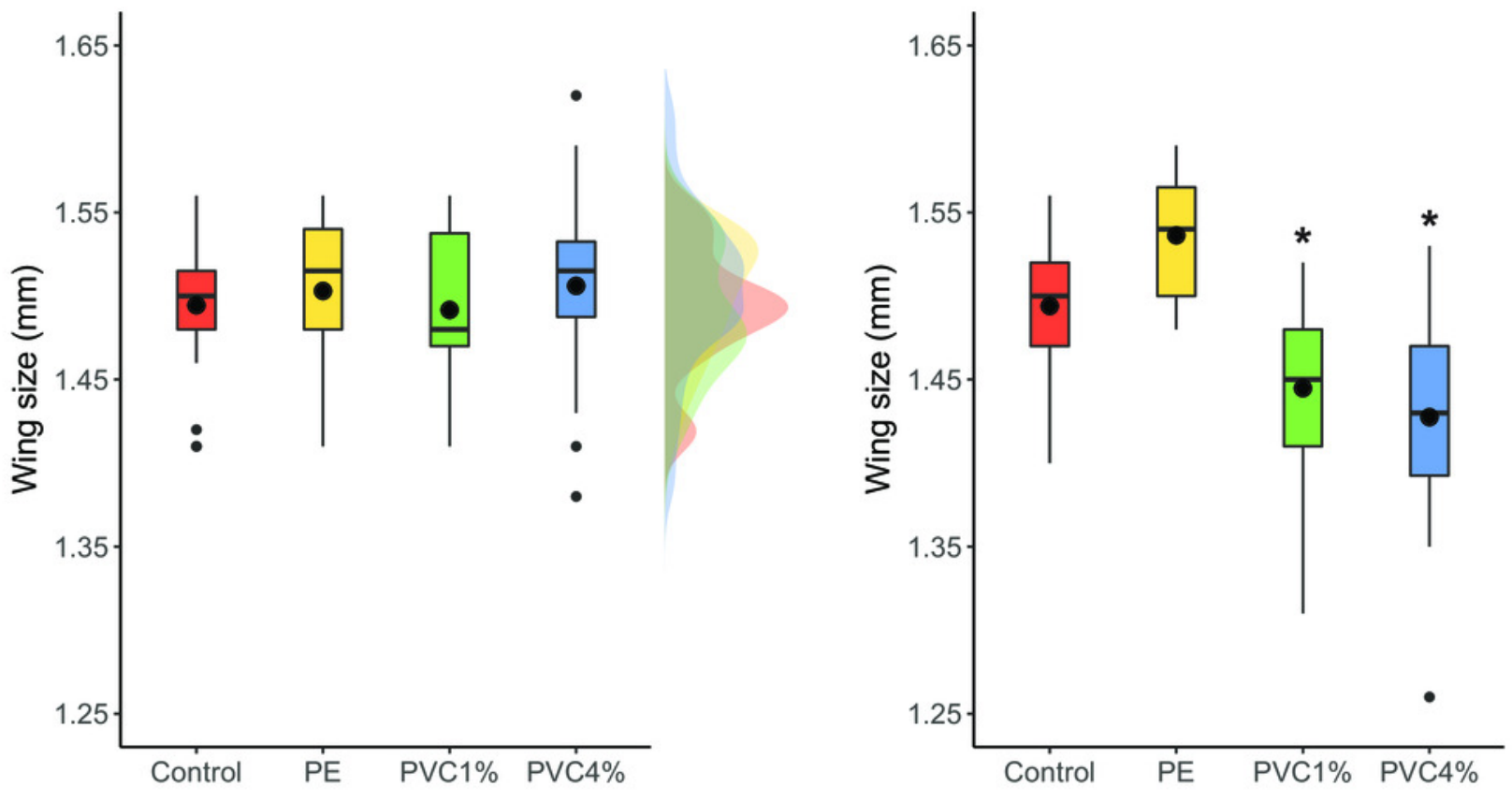